\title{
Spinal Vascular Malformations
}

\section{Diagnostic and Therapeutic Management}

\author{
Timo Krings ${ }^{1,2}$, Pierre L. Lasjaunias ${ }^{2}$, Marcus H.T. Reinges ${ }^{1}$, Michael Mull', \\ Franz J. Hans ${ }^{1}$, Armin K. Thron ${ }^{1}$
}

\begin{abstract}
Spinal vascular malformations are rare diseases with a wide variety of neurological presentations. In this article spinal cavernomas, arteriovenous malformations (both from the fistulous and glomerular type), and spinal dural arteriovenous fistulae are described and an overview about their imaging features on magnetic resonance imaging (MRI) and digital subtraction angiography is given. Clinical differential diagnoses, the neurological symptomatology and the potential therapeutic approaches of these diseases which vary depending on the underlying pathology are given. Although MRI constitutes the diagnostic modality of first choice in suspected spinal vascular malformation, a definite diagnosis of the disease and therefore the choice of suited therapeutic approach rest on selective spinal angiography. Treatment in symptomatic patients offers an improvement in the prognosis. In most spinal vascular malformations except for spinal cavernomas, the endovascular approach is the method of first choice; in selected cases a combined or surgical therapy might be considered.
\end{abstract}

Key Words: Spinal vascular malformation · Spinal arteriovenous malformations · Spinal cavernoma · Spinal dural arteriovenous fistula

Clin Neuroradiol 2006;16:217-27

DOI: $10.1007 / \mathrm{s} 00062-006-6026-9$

\section{Spinale vaskuläre Malformationen: Diagnostik und Therapie}

\section{Zusammenfassung}

Spinale vaskuläre Malformationen sind seltene Erkrankungen, die mit einer Vielzahl neurologischer Symptome einhergehen können. In diesem Artikel wird die Bildgebung (MRT und Angiographie), aber auch die Pathophysiologie von spinalen Kavernomen, arteriovenösen Malformationen (sowohl vom glomerulären wie auch vom fistulösen Typ) und spinalen duralen arteriovenösen Fisteln beschrieben. Die klinischen Differentialdiagnosen, die neurologische Symptomatik und mögliche therapeutische Ansätze werden ebenso dargestellt. Obwohl bei dem Verdacht auf eine spinale vaskuläre Malformation die MRT die diagnostische Bildgebung der ersten Wahl darstellt, muss zur abschließenden Diagnostik, Klassifikation und damit auch zur therapeutischen Planung eine selektive spinale Angiographie in DSA-Technik erfolgen. Eine Behandlung symptomatischer Patienten kann in den meisten Fällen die Prognose günstig beeinflussen. Mit der Ausnahme spinaler Kavernome ist dabei die endovaskuläre Behandlung für die meisten spinalen vaskulären Malformationen der therapeutische Ansatz der Wahl; nur in ausgewählten Fällen kann auch eine kombinierte oder rein chirurgische Therapie diskutiert werden.

Schlüsselwörter: Spinale vaskuläre Malformation · Spinale arteriovenöse Malformationen · Spinales Kavernom • Spinale durale arteriovenöse Fistel

\footnotetext{
${ }^{1}$ Departments of Neuroradiology and Neurosurgery, University Hospital Aachen, Germany,

${ }^{2}$ Service de Neuroradiologie Diagnostique et Thérapeutique, Hôpital de Bicetre,

Le Kremlin-Bicetre, Paris, France
} 


\section{Introduction}

Spinal vascular malformations are rare and still underdiagnosed entities that, if not treated properly, can lead to considerable morbidity with progressive spinal cord symptoms. Their clinical diagnosis rests mainly on magnetic resonance imaging (MRI), while for a thorough understanding of the diseases and for planning the therapeutic strategy, selective spinal subtraction angiography (DSA) still is necessary. Depending on the type of spinal vascular lesion, initial symptoms may vary between acute or chronic onset. Pathophysiologic mechanisms include intramedullary or subarachnoid hemorrhages or subacute venous congestion leading to progressive myelopathy. The space-occupying nature of some of these lesions and a circulatory "steal" phenomenon are additional possible pathophysiologic mechanisms. While acute manifestations of spinal vascular malformations typically lead to a diagnosis early in the course of the disease, the subacute venous congestion might lead to unspecific neurological symptoms which in turn delay proper diagnosis. The aim of the following article is to review the imaging features, clinical symptomatology and potential therapeutic approaches of spinal vascular malformations and to remind both the neuroradiologist and the referring physician that the diagnosis and subsequent treatment of these treatable causes of severe and otherwise progressive neurological deficits still remain a challenge.

Since an understanding of spinal vascular malformations both from an etiological and from a pathophysiological standpoint is based on the spinal vascular anatomy, we will briefly describe the salient features of spine and spinal cord arterial supply and venous drainage in the following section.

\section{Spinal Vascular Anatomy}

Segmental arteries (i.e., segmental feeders from the vertebral arteries, the deep and ascending cervical arteries for the cervical levels; intercostal or lumbar arteries at the thoracic and lumbar levels; and, for the sacral levels the ileolumbar arteries) supply the spine (including the vertebral bodies, paraspinal muscles, dura, and nerve roots) and the spinal cord with blood. The bony spine is supplied by anterior and posterior central arteries that arise directly from the segmental and radicular arteries. A spinal radicular branch supplying the dura and the nerve root as a radiculomeningeal artery is present at each segment. From these radicular arteries, radiculomedullary and/or radiculopial arteries might branch, following the anterior or posterior nerve root to reach the anterior or posterior surface of the cord, where they form the anterior or posterior spinal artery [1]. In the adult patient, not all lumbar or intercostal arteries have a radiculomedullary or radiculopial feeder, and their location for a given patient is not predictable. The anterior and posterior spinal arteries constitute a superficial longitudinal anastomosing system [2]. The anterior spinal artery travels along the anterior sulcus and typically originates from the two vertebral arteries, while the typically paired posterolateral spinal arteries originate from the preatlantal part of the vertebral artery or from the postero-inferior cerebellar artery (PICA). These three arteries run from the cervical spine to the conus medullaris, but are not capable to feed the entire spinal cord. Instead, they are reinforced from the above-mentioned radiculomedullary arteries that derive from various (and unpredictable!) segmental levels by anterior and posterolateral radiculomedullary arteries [3]. The most well known of the anterior radiculomedullary arteries is the Arteria radiculomedullaris magna (i.e., the Adamkiewicz artery). The anterior radiculomedullary arteries branch in a very typical way to reach the spinal cord. The ascending branch continues along the direction of the radicular artery in the midline of the anterior surface. The descending branch, being the larger one at thoracolumbar levels, forms a hairpin curve as soon as it reaches the midline at the entrance of the anterior fissure [1].

The intrinsic network of the spinal cord arteries can be divided in central or sulcal arteries from the anterior spinal artery on the one hand, and on the other hand in the rami perforantes of the vasa corona that supply the periphery of the spinal cord and are derived both from the anterior and from the paired posterolateral arteries [2].

The venous drainage of the cord is via radially symmetric intrinsic spinal cord veins and small superficial pial veins that open into the superficial longitudinal median anastomosing spinal cord veins. These veins are following more or less the arteries, i.e., the anterior and posterior median spinal vein but have many anastomoses (including transmedullary anastomoses) creating a network with commonly more than one anterior and posterior vein [3]. They are also using the roots as a vehicle to reach the epidural plexus and the extraspinal veins and plexus with a reflux-impeding mechanism within the dura mater [4]. It is important to note that the transition of a median vein into a radicular vein shows 
the same hairpin-shape as the artery. At the superior cervical part, they can run through the occipital foramen to connect the vertebral plexus or the inferior dural sinus. Drainage of blood from the spine occurs through the valveless internal and external venous vertebral plexus that is connected to the azygos and hemiazygos venous systems.

\section{Classification of Spinal Vascular Malformations}

Multiple different classification schemes have been proposed for spinal vascular malformations. Recently, the Bicetre group classified spinal cord arteriovenous malformations into three main groups [5]:

1. Genetic hereditary lesions that are caused by a genetic disorder affecting the vascular germinal cells. Spinal cord malformations associated to hereditary haemorrhagic telangiectasia (HHT) fall into this category.

2. Genetic non-hereditary lesions that share metameric links such as the Cobb syndrome (or spinal arteriovenous metameric syndrome) that affects the whole myelomere. These patients typically present with multiple shunts of the spinal cord, the nerve root, bone, paraspinal, subcutaneous, and skin tissues. KlippelTrenaunay and Parkes-Weber syndromes also belong to this group.

3. Single lesions that may reflect the incomplete expression of one of the previous mentioned situations and that include spinal cord, nerve root, and filum terminale lesions.

Since the majority of spinal vascular malformations fall into the last group, and for practical therapeutic reasons, in the following we use a classification that is based on the vascular anatomy of the spinal cord as described above and the inborn or acquired nature of the lesion [6]. According to this classification, spinal vascular malformations can be differentiated, similar to vascular malformations of the brain, into the true inborn lesions and the acquired lesions, the latter being the dural arteriovenous (AV) fistulae, whereas arteriovenous malformations (AVM) and cavernomas constitute the inborn lesions of the spine [7]. In contrast to the brain, where capillary teleangiectases also belong to the inborn lesions, they have not been found yet in the spine and will, therefore, not be further discussed.

Spinal cord AVMs are like their cerebral counterparts shunts that are fed by arteries normally supplying the neural tissue, i.e., the intrinsic arteries of the spinal cord whereas spinal cord dural AV fistulae (like their cranial counterparts, the dural AV fistulae) are fed by radiculomeningeal arteries (which are in fact similar to meningeal arteries) [7].

\section{Dural AV Fistulae}

Spinal dural arteriovenous fistulae (SDAVF) are the most frequent vascular malformation of the spine and account for $70 \%$ of all AV shunts of the spine [7]. They are presumably acquired lesions, however, the exact etiology is not known. Usually, the disease becomes symptomatic in elderly men (between 40-60 years) [8]. Most fistulae are found in the thoracolumbar region.

The arteriovenous shunt is located inside the dura mater close to the spinal nerve root where the arterial blood from a radiculomeningeal artery (i.e., an artery supplying the root and meninges but not necessarily the spinal cord!) enters a radicular vein where the latter passes the dura. The increase in spinal venous pressure diminishes the arteriovenous pressure gradient and leads to a decreased drainage of normal spinal veins and a venous congestion with intramedullary edema $[9,10]$. This in turn leads to chronic hypoxia and progressive myelopathy [11]. Clinical symptomatology of this congestive myelopathy is rather unspecific and might consist of hypo- and paraesthesias, paraparesis, back pain that might irradiate to the lower legs, impotence, and sphincter disturbances. Usually, the deficits are slowly progressive; however, an acute onset of the disease and a progressive development interrupted by intermediate remissions is also possible [7, 12]. Without therapy, this disease results in irreversible para- or even tetraplegia.

On MRI the combination of cord edema and perimedullary dilated vessels are the characteristic findings and should lead to the diagnosis [12]. On T2-weighted sequences, the cord edema is depicted as a centromedullary, not well delineated hyperintensity over multiple segments that is often accompanied by a hypointense rim, most likely representing deoxygenated blood within the dilated capillary vessels surrounding the congestive edema [13]. The cord is swollen and might demonstrate contrast enhancement as a sign for chronic venous congestion [14] (Figures 1A, 1B and 2). In the further course of the disease, the cord will get atrophic. The perimedullary vessels are dilated and coiled and can be observed on the T2-weighted images as flow voids. However, if the shunt volume is small, they might only be seen after contrast enhancement. Neither the location of pathological vessels nor the intramedullary imaging findings seem to be related to the height of the fistula. Localisa- 
tion of the fistula can sometimes be very difficult leading to lengthy and even multiple catheterisation procedures during spinal DSA. Therefore non-invasive diagnostic

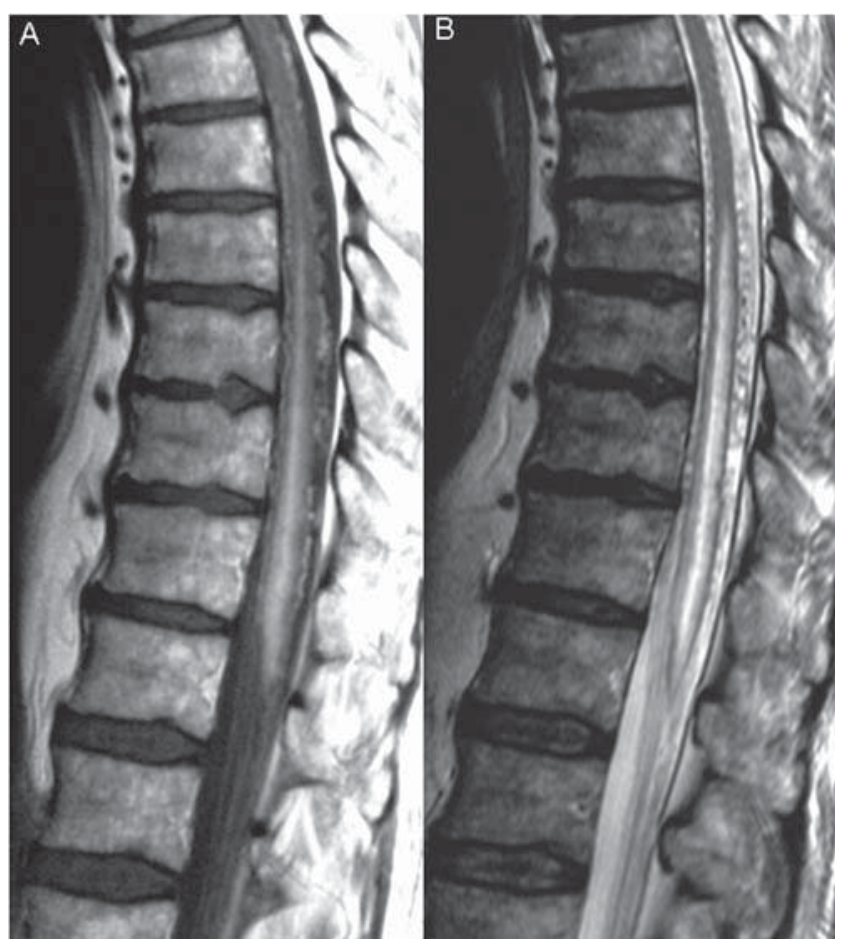

techniques, such as contrast-enhanced MR angiography with relative fast acquisition protocols have been developed [24-26].

There are two options in the treatment of SDAVF: surgical occlusion of the intradural vein that receives the blood from the shunt zone - a relatively simple and safe intervention with exception of sacral fistulae [15, $16]$; or endovascular therapy employing glue after superselective catheterisation of the feeding radiculomeningeal artery $[17,18]$. The embolic agent must pass the nidus and reach and occlude the proximal segment of the draining vein in order to prevent subsequent intradural collateral filling of the fistula. Therefore, success rates of endovascular therapy have been reported to vary between 25 and $75 \%$ [17, 19]. Following complete occlusion of the fistula, the progression of the disease can be stopped; however, only two thirds of all patients have a regression of their motor symptoms and only one

Figures $\mathbf{1 A}$ and $\mathbf{1 B}$. MR imaging findings in a spinal dural arteriovenous fistula. On T1-weighted images after contrast injection dilated and tortuous perimedullary vessels can be seen (A), which are in T2weighted images visible as pathological flow voids along the dorsal surface of the spinal cord (B). A contrast enhancement of the conus as a sign for subacute venous infarction can be assessed and there is extensive edema within the cord.

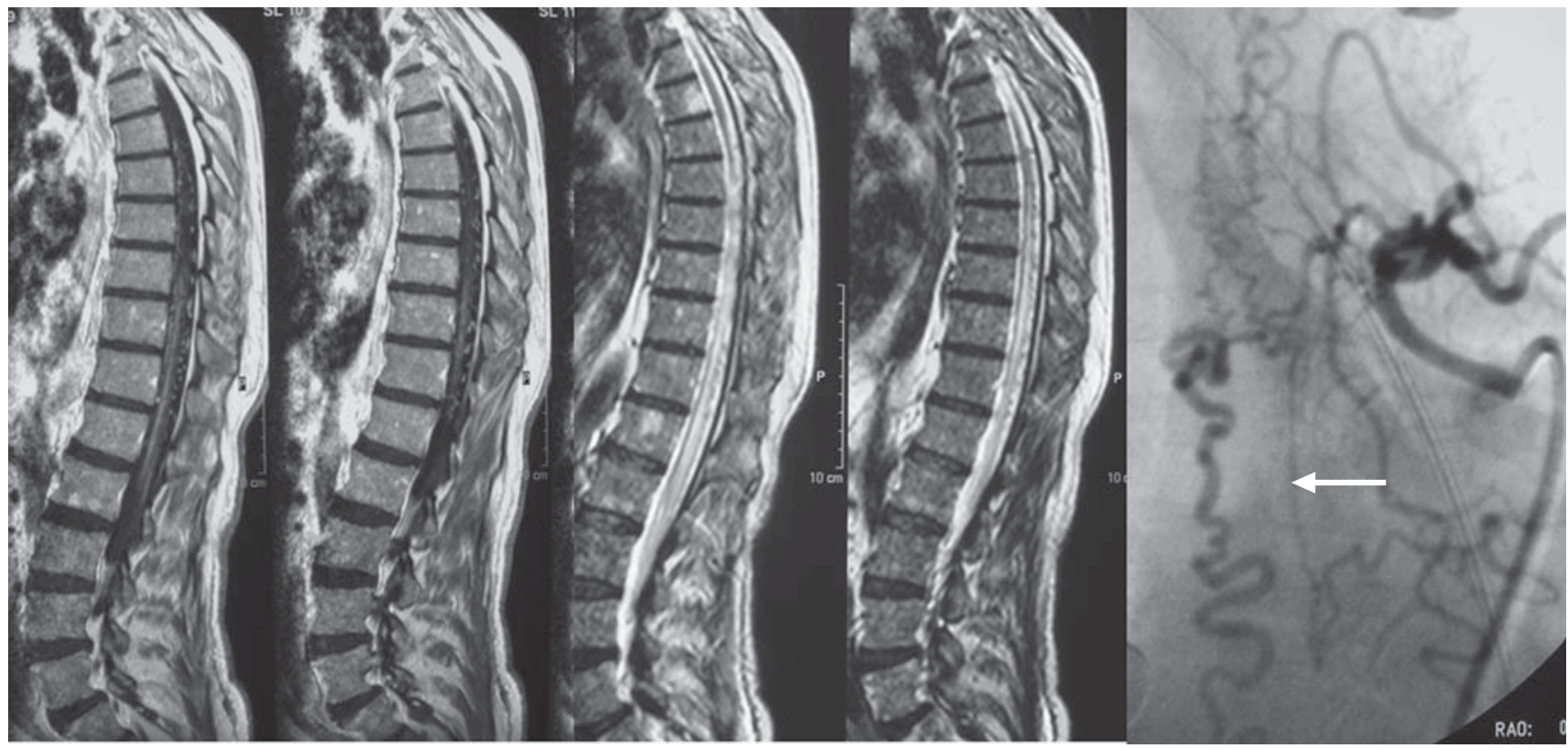

Figure 2. Spinal dural arteriovenous fistula: MRI and DSA. On T2-weighted images, cord edema and perimedullary flow voids can be assessed; after contrast enhancement, the perimedullary vessels can be even better assessed. The combination of pathologically dilated vessels and edema of the cord is pathognomonic for spinal dural AV fistulae; angiography, however, is necessary to define the exact height of the fistula and to rule out a small perimedullary fistula. After injection into the left Th6 intercostal artery, the fistulous zone can be assessed that also receives blood from a small ascending dural branch (arrow) and that drains into two distinct veins. 


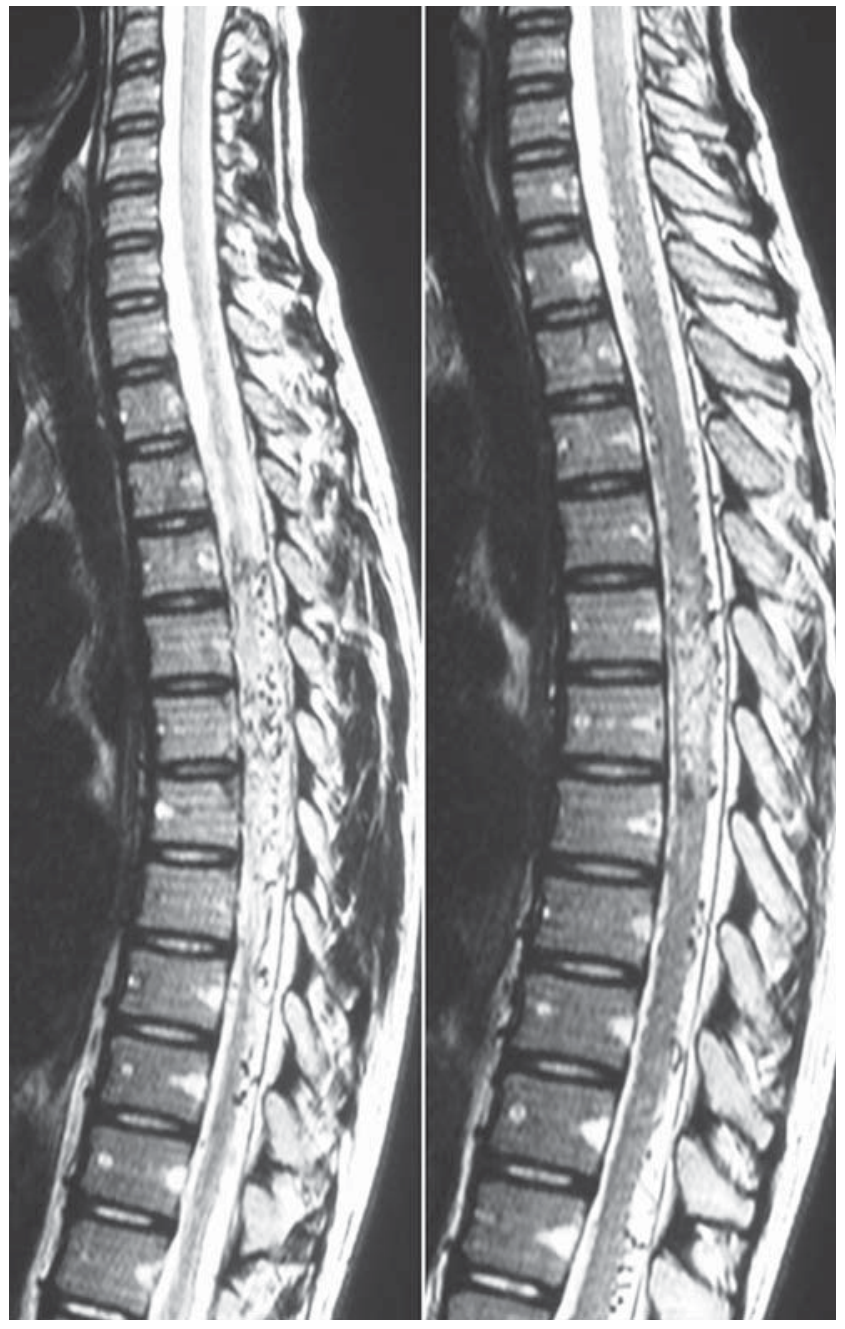

Figure 3. Spinal glomerular AVM: On T2-weighted images, the flow voids can be easily identified. MRI also demonstrates the location of the nidus within the cord with some perifocal edema present.

third show an improvement of their sensory disturbances. Impotence and sphincter disturbances are seldom reversible [20].

\section{Spinal Cord AVMs}

Spinal cord AVMs are fed by radiculomedullary and/ or radiculopial, i.e., spinal cord feeding arteries and drained by spinal cord veins. These shunts might be intra- and/or perimedullarily located and can be differentiated according to their transition from artery into vein into fistulous and glomerular AVMs [21].

Glomerular AVMs (which are sometimes called plexiforme or nidus-type AVMs) are the most often encountered spinal cord AVM with a nidus resembling closely those of a brain AVM. This type of malformation usually is located intramedullarily; superficial nidus compartments can, however, also reach the subarachnoid space. Because of the many anastomoses between the anterior and posterior intrinsic arterial system of the spine, these AVMs have typically multiple feeding arteries derived from both the posterior and anterior system. The drainage is directed into dilated spinal cord vessels (Figures 3 to 6).

Fistulous AVMs (which are also called AVM of the perimedullary fistula type or intradural AV fistulae) are direct arteriovenous shunts located superficially on the

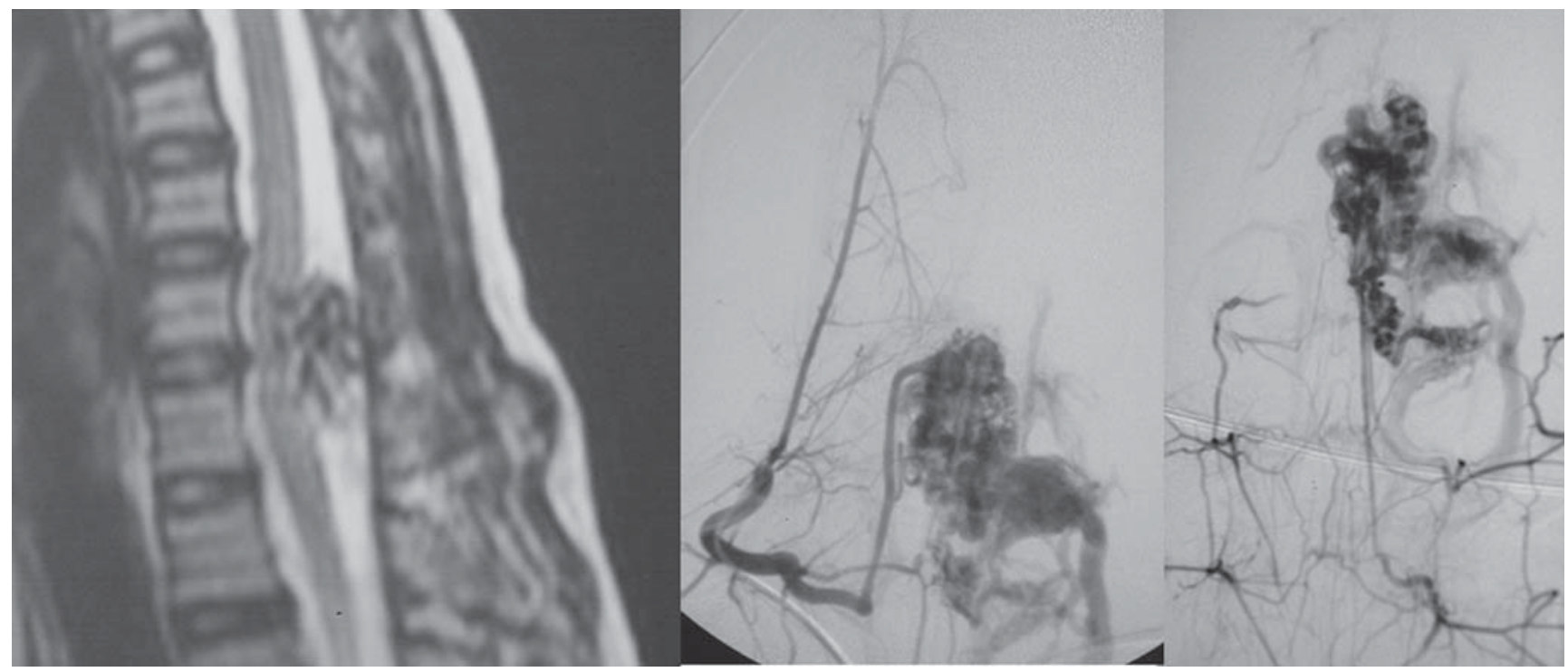

Figure 4. Spinal glomerular AVM. This AVM is located mainly extramedullary as shown by MRI and the angioarchitecture with dominant pial supply. 
spinal cord and only rarely possess intramedullary compartments [22]. Feeding vessels are again radiculomed-

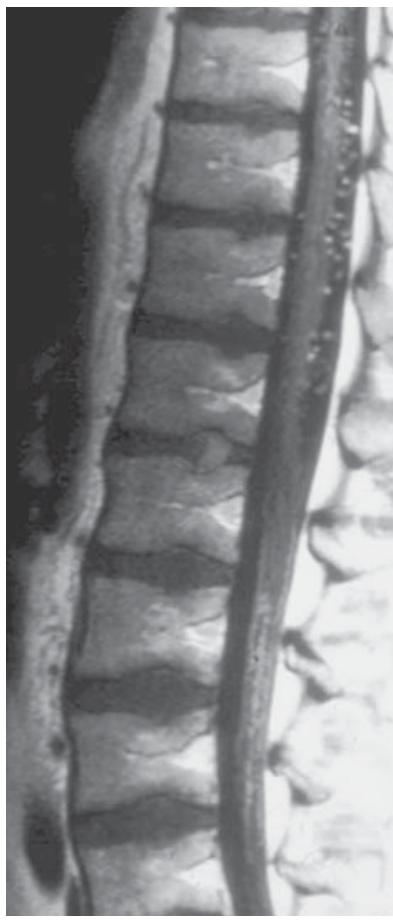

Figure 5a

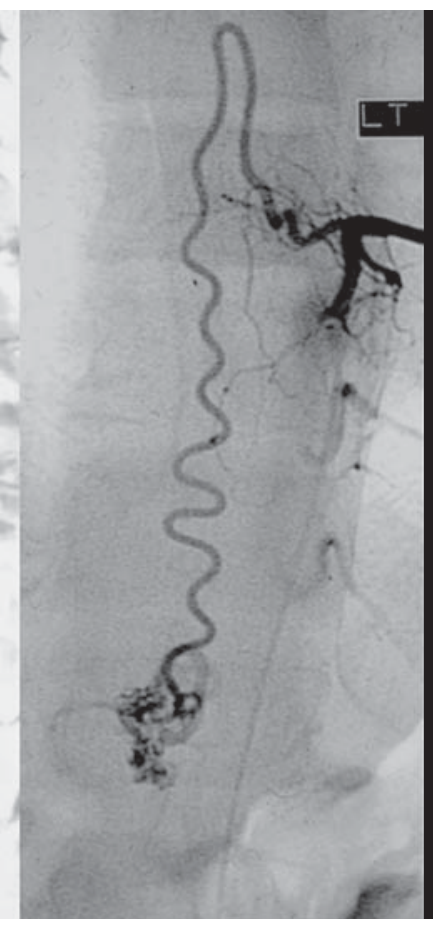

Figure 5b ullary arteries (which differentiates them from the dural

AV fistulae where radiculomeningeal arteries are the

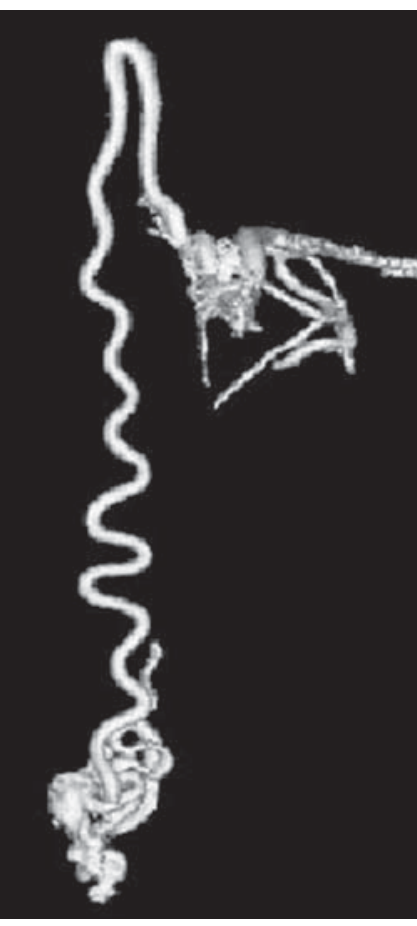

Figure $5 c$
Figures $\mathbf{5 a}$ to $\mathbf{5 c}$. This 19-year-old male presented with subacute onset of progressive weakness of both legs over a three-months period. MRI demonstrated increased signal within the conus and multiple flow voids along the spinal cord, which enhanced with contrast (a). Ventral spinal arterial supply was demonstrated towards a SCAVM located along the posterior aspect of the conus with venous drainage directed upwards to the thoraco-cervical level $(b, c)$. feeders). Draining veins are superficial perimedullary veins. The arterialized blood sometimes even ascends via the foramen magnum into the posterior fossa (Figures 7 to 10$)$.

Depending on the size of the feeding vessels, the shunt volume and the size of the draining veins, these fistulae can be further categorized into those with a low shunt volume and only moderately enlarged feeding veins and arteries, and those with a high shunt volume that lead to a massive remodelling of the blood vessels with enlarged arteries, and dilated venous pouches. The latter types are typically encountered in children with a history of hereditary hemorrhagic telangiectasia [23].

Pathophysiologic mechanisms in spinal cord AVMs

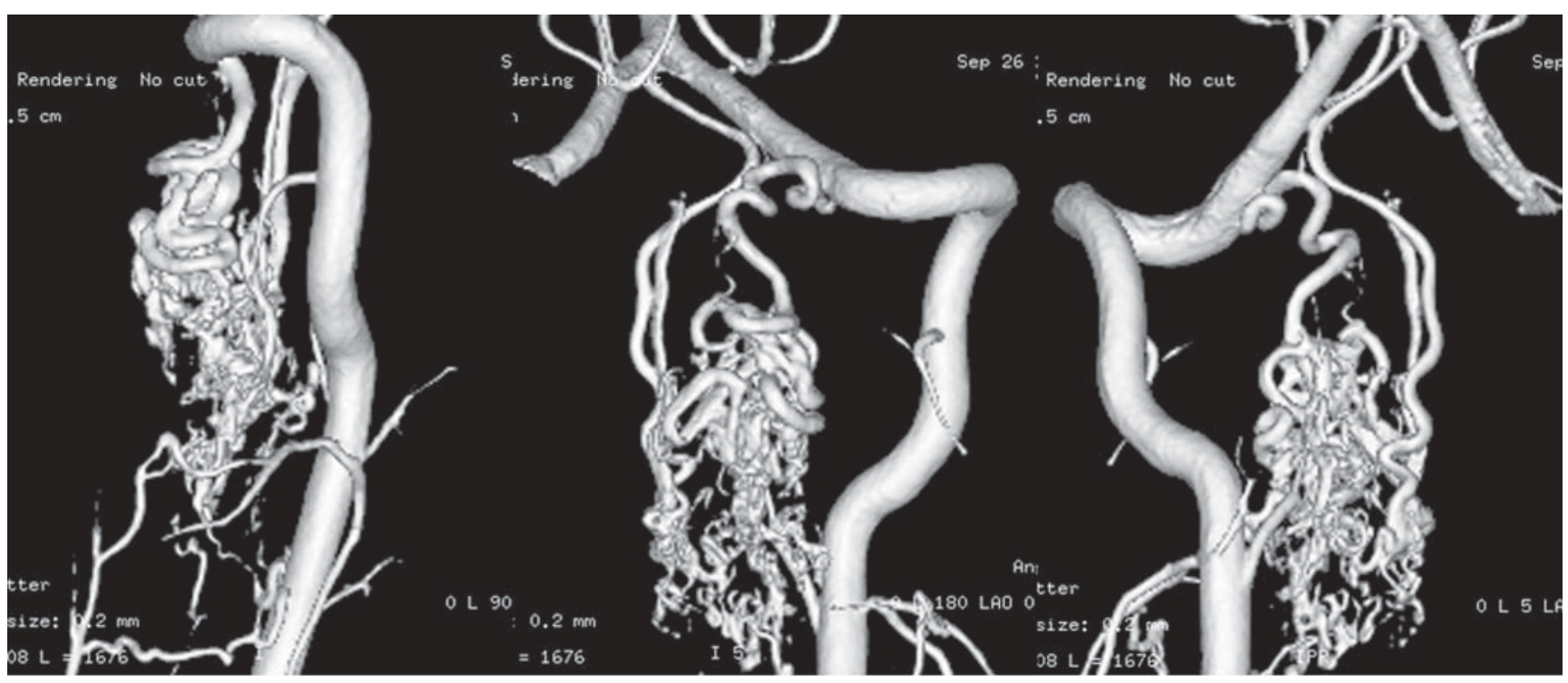

Figure 6.3D rotational angiography in a patient with a cervical glomerular AVM can detect the different feeders and the intrinsic angioarchitecture and might therefore be helpful for identifying intranidal aneurysms. 


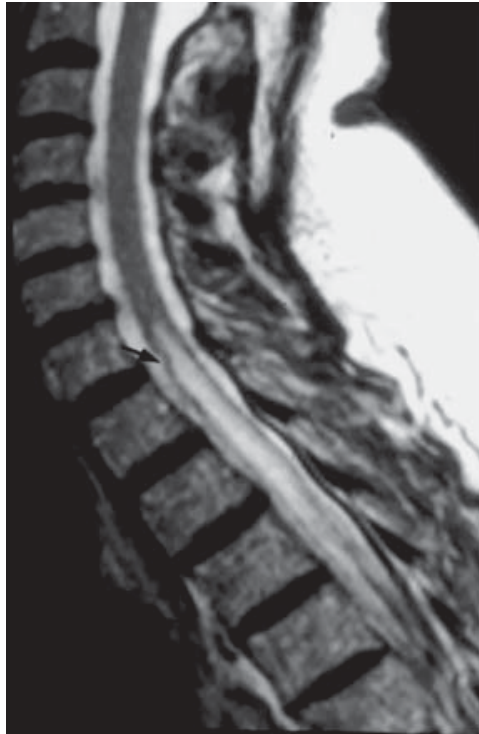

Figure $7 a$

Figure $\mathbf{7 b}$

Figures $\mathbf{7 a}$ and $\mathbf{7 b}$. MR-occult (a) symptomatic perimedullary fistula (b):Ventrally located drainage within the ventral subpial space in a patient with MRI evidence of venous congestion but without evidence of perimedullary dilated veins owing to the subpial venous drainage. The arrows point to the fistulous site, the arrowheads denote the draining vein that was responsible for the congestion.

include venous congestion and hemorrhage; space occupying effects and "steal-phenomena" have also been attributed to the pathogenesis [24,25]. If the AVM does not present initially with an acute hemorrhage, symptomatology is unspecific. Patients may complain about hyp- or paraesthesia, weakness and diffuse back and muscle pain. Progressive sensorimotor symptoms can slowly develop, or acutely worsen followed by some improvements over time. While fistulous AVMs often get symptomatic with a subarachnoid hemorrhage due to their intradural perimedullary location, glomerular AVMs can become symptomatic by venous congestion alone [26], by intraparenchymal and/or a subarachnoid hemorrhage.

On MRI, the AVM type can not always be differentiated. The typical appearance of spinal cord AVMs is a conglomerate of dilated, peri- and intramedullary located vessels that are demonstrated on T2-weighted sequences as flow voids, while they appear on T1-weighted sequences depending on their flow velocity and direction as mixed hyper-hypointense tubular structures. Contrast enhancement may vary. A venous congestive edema may be present as an intramedullary hyperintensity on T2-weighted images with concomitant swelling of the cord. The image might get even more complicated if intraparenchymal hemorrhages are present that might demonstrate varying signal intensities depending on the time elapsed between bleeding and imaging [27]. A subarachnoid hemorrhage might be present. MR imaging should be able to identify the location of the AVM in relation to the cord and the dura. Especially in low flow perimedullary fistulous AVMs, contrast media must be given to detect subtle venous dilatations $[12,28,29]$. Recently, it has been shown that fast MR angiography is capable to detect the main arterial feeder of glomeru-

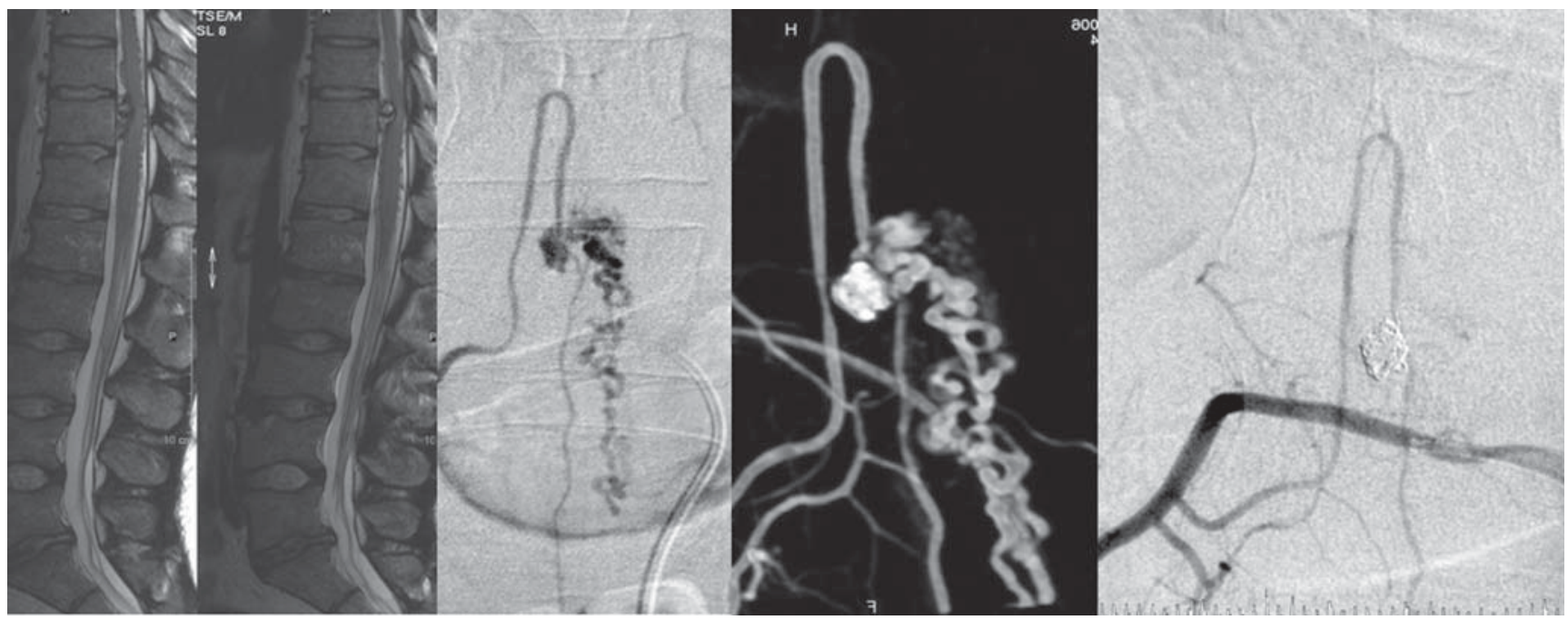

Figure 8. MR, angiography and treatment of a perimedullary fistula that got symptomatic with a spinal subarachnoid hemorrhage, presumably from the venous ectasia that was present at the fistulous site. Treatment of the aneurysm with coils was performed that led to complete obliteration of the fistula and vascular remodelling of the anterior spinal artery on follow-up. 


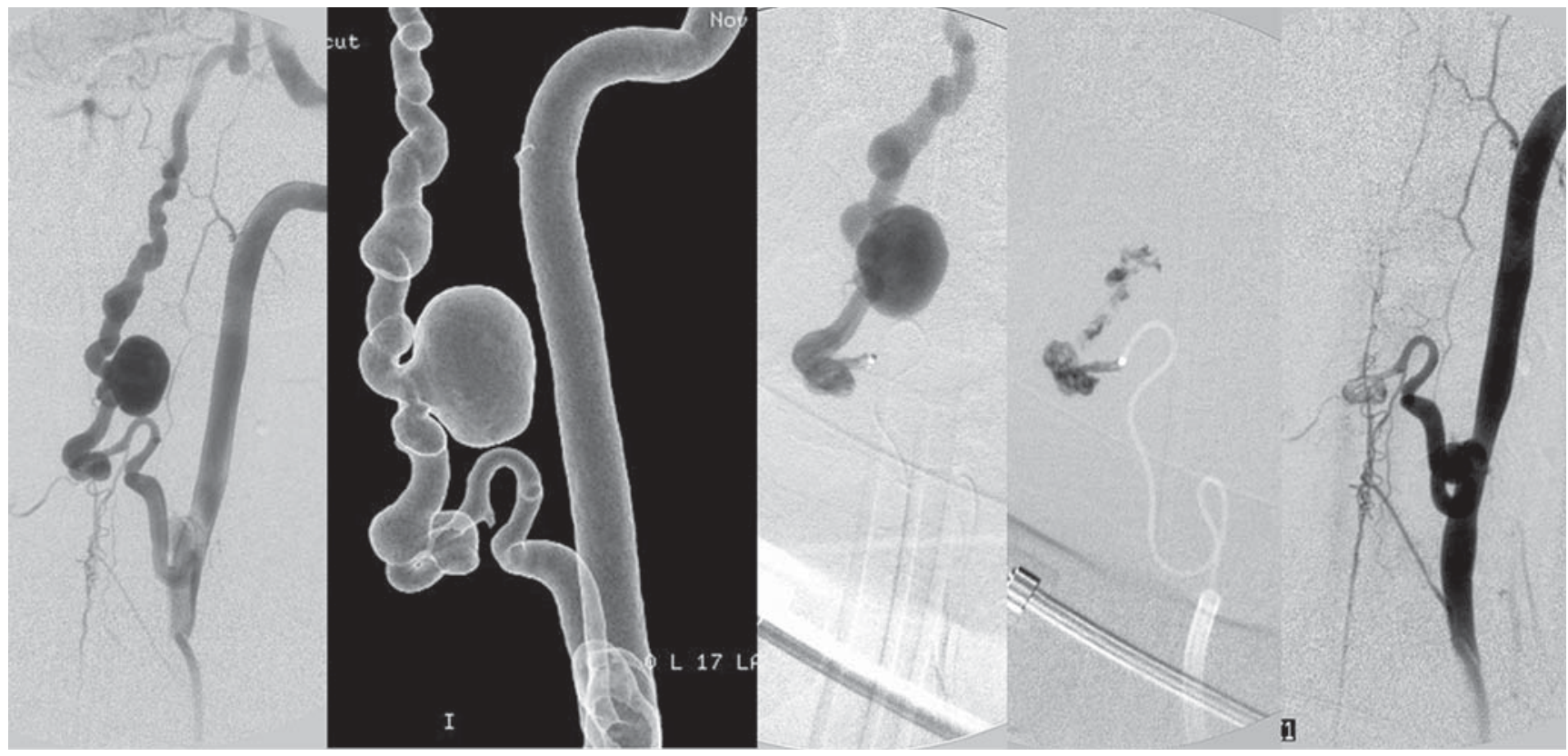

Figure 9. This perimedullary fistula was revealed by progressive peripheral neurological deficits in a 24-year-old female. Arterial supply came from a sulco-commissural feeder of the anterior spinal artery: in this case the venous ectasia was located distal to the fistulous zone. After NBCA embolisation, the anterior spinal axis is still opacified while the venous ectasia and the fistula are obliterated.

lar-type AVMs and perimedullary fistulous-type AVMs with a single large arterial feeder. Spinal cord AVMs with small or multiple feeders have not yet been investigated. Therefore, selective spinal angiography remains necessary to define the exact type of the AVM and to plan subsequent treatment.
The therapeutic approach of asymptomatic AVM is difficult since data concerning the spontaneous prognosis are not available; however, in symptomatic AVMs therapy ameliorates the prognosis of the patient. The therapy of choice for all spinal cord AVMs is the endovascular embolisation with coils, glue or particles after
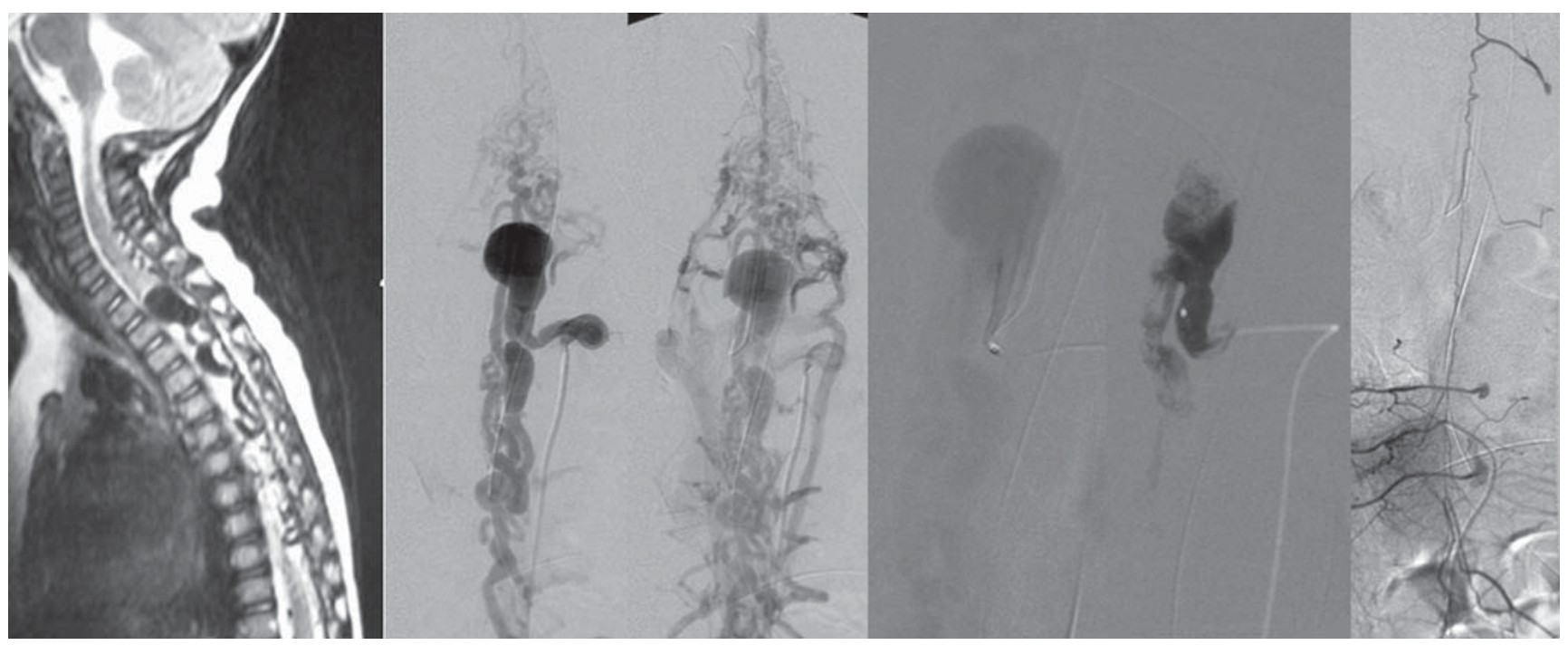

Figure 10. MR and angiography in a spinal vascular malformation in a patient with hereditary hemorrhagic telangiectasia. The fistula can be classified as a high-flow perimedullary fistula with massively enlarged inflow and outflow tracts. Treatment is performed with pure glue injection (mixed with Tantalum powder) in a mushroom-shape to obliterate the most proximal part of the venous outflow. 
careful analysis of the selective spinal angiography [30] with the embolising agent being dependent on the specific angioarchitecture.

In glomerular AVMs, glue or particles can be employed to obliterate the nidus, even a partial embolisation seems to ameliorate the prognosis of the patient [7, 31-33]. In low-flow perimedullary fistulae, glue or sometimes even coils at the fistula zone can be used with the aim of obliterating the most proximal part of the venous receptacle. A proximal arterial occlusion on the other hand will not be successful because of collateral recanalisation from the radiculopial network. If, therefore, the proximal venous segment can not be reached by the glue cast or the coils, endovascular therapy should be avoided and a surgical attempt may be favoured. Large high-flow fistulous AVMs can easily be reached by superselective catheterisation close to the fistula and subsequent closure (typically with concentrated glue or coils) is in nearly all instances possible [34, 35]. Again, the aim is to occlude the most proximal of the venous part, which in case of glue can be performed using a "mushroom-shaped" glue cast.

\section{Cavernomas}

Spinal cord cavernomas (or cavernous malformation) are estimated to constitute $5 \%$ of all spinal vascular malformations [36, 37]. Like their intracranial counter- parts, cavernomas are on gross pathology discrete, lobulated, well-circumscribed, red to purple raspberry-like lesions. Microscopically, these lesions are composed of dilated, thin-walled capillaries that have a simple endothelial lining with variably thin fibrous adventitia indistinguishable from the lining of a capillary telangiectasia [38]. Residua of previous hemorrhage, including scarring, collection of hemosiderin-laden macrophages, and calcification may be present [39]. Typical clinical features of intramedullary cavernous malformations are sensorimotor deficits, usually several hours after the onset of pain. The clinical course is variable, ranging from slowly progressive symptoms to acute quadriplegia. The acute setting is probably caused by new hemorrhage within or around the lesion. Repeated episodes of small bleedings, or local pressure effect of the lesion itself on the surrounding spinal cord tissue by capillary proliferation, and vessel dilatation may be responsible for slowly progressive symptoms.

Cavernomas appear as well-defined, circumscribed lesions of varying sizes, that have a hypointense rim and an inhomogeneous, often hyperintense center on T2weighted images. The hypointense rim is due to magnetic susceptibility artefacts from hemosiderin deposits [40]. The complex reticulated core with its typical mulberry-like appearance represents hemorrhage in different stages of evolution (Figures 11 to 12). Computed

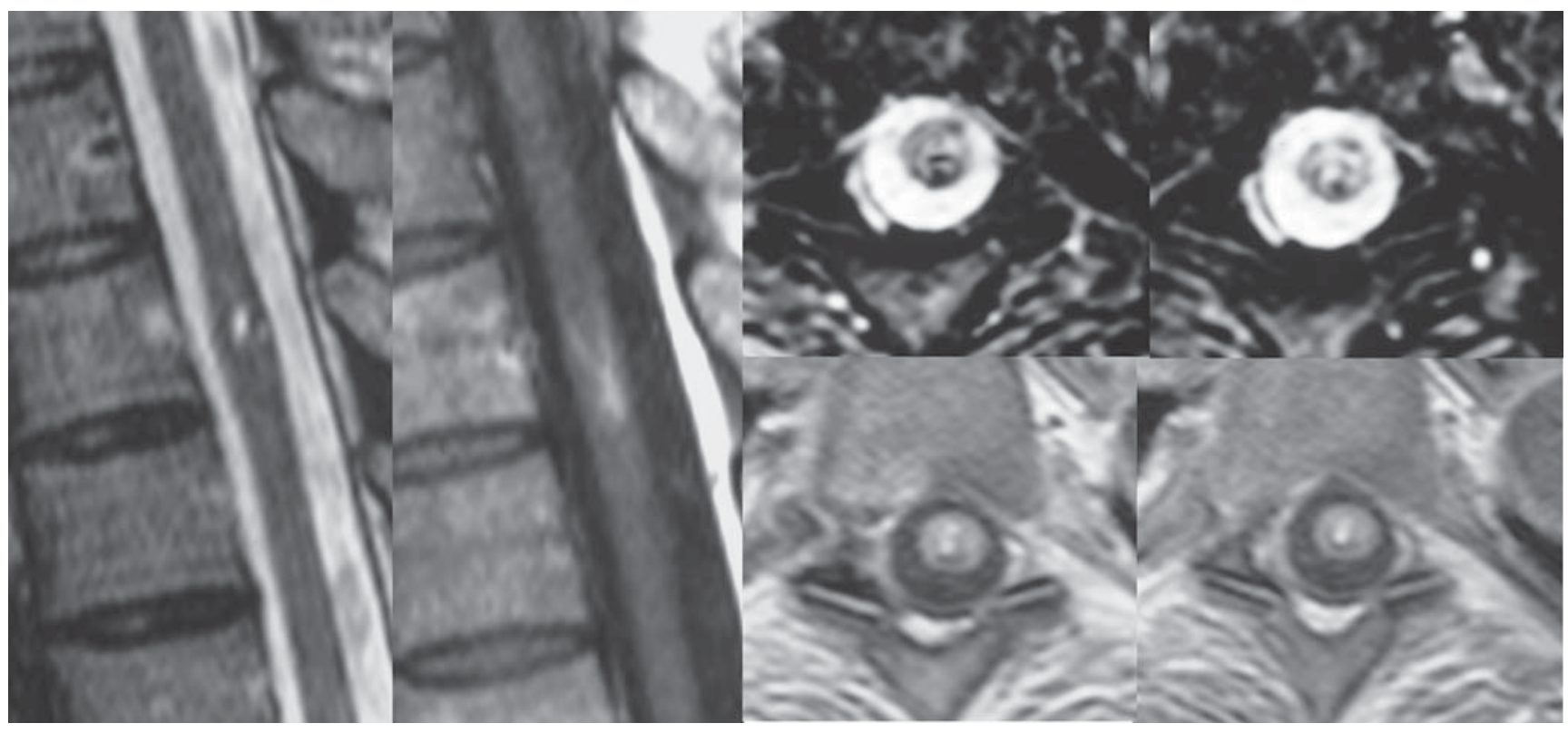

Figure 11. Thoracic cavernoma of a 46-year-old woman with radicular pain. Sagittal T1- and T2-weighted MRI demonstrate an intramedullary lesion with high peripheral signal intensity on T1w (a). The lesion is of mixed intensity in T2-weighted images and leads to a slight extension of the cord. The mixed intensity both on T1- and T2-weighted images testifies for blood degradation products in different stages. 


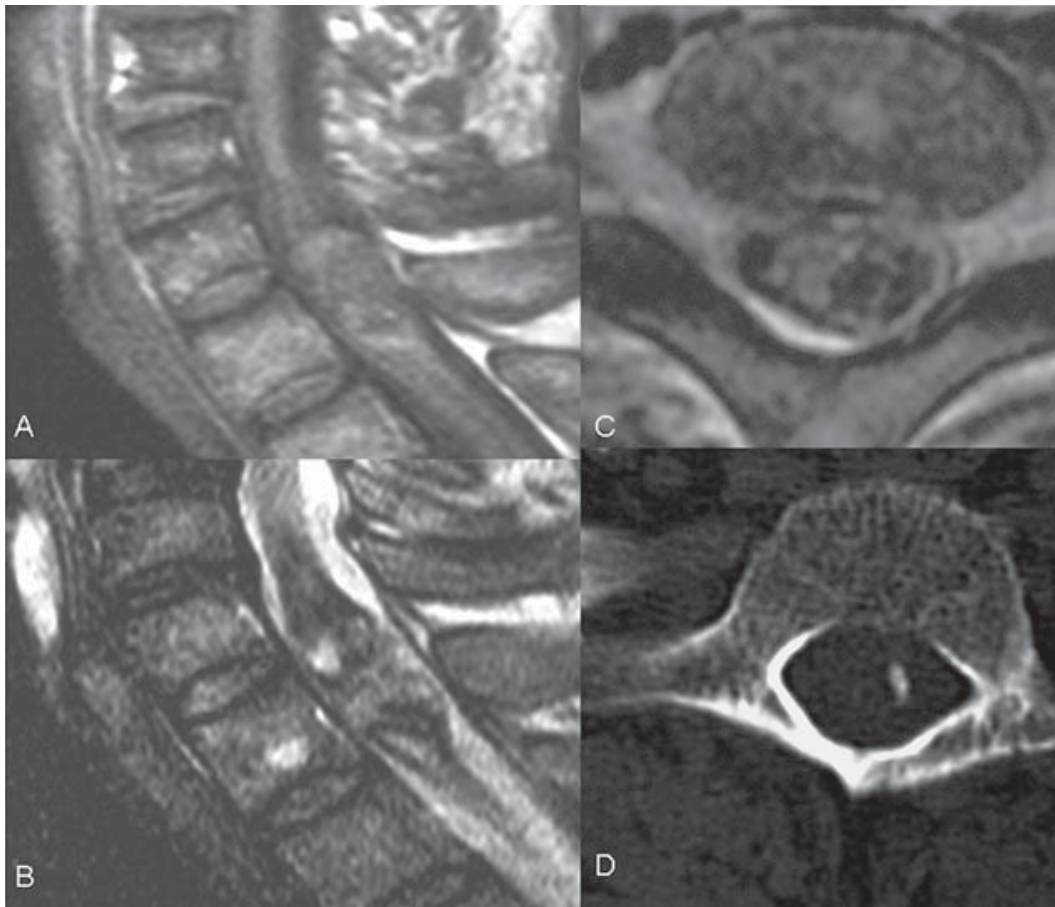

Figure 12. Large, partly calcified cavernoma with mixed signal intensity on T2- and T1weighted images.

tomography might be of interest, since some cavernomas demonstrate extensive calcifications. Cavernomas are angiographically silent. However, in acutely hemorrhaged cavernomas, spinal angiography should be performed to rule out that a small glomerular AVM that might remain unnoticed on spinal MRI in the acute phase after hemorrhage was the culprit for the bleeding.

Once the lesion gets symptomatic, progressive myelopathy is the most common course [41].

Therefore, therapy is indicated. Surgical resection of cavernomas can be performed safely using meticulous microsurgical techniques. The localisation of the cavernous malformation is mandatory to define the adequate operative strategy. Dissection is started directly over the lesion if the pathology approaches the surface of the cord. Deeply located lesions are either approached by a myelotomy performed over an area of bluish discoloration or by standard approaches, i.e., through the dorsal root entry zone or by a midline myelotomy. Then surgery is continued by gradual debulking of the mass. Dissection of the cavernous malformation is achieved by slight traction, coagulation and gentle suction in the surrounding yellow plane of gliotic tissue preventing damage to the neighbouring intact nervous tissue [41]. The lesion bed should be carefully inspected after resection for small residual portions.

\section{Conclusions}

The unspecific neurological symptomatology and the variety of potentially detected vascular malformations make this clinical entity challenging both for the neurologist/neurosurgeon and the neuroradiologist. When spinal vascular diseases are suspected, MRI should constitute the first diagnostic modality to identify the lesion and rule out potential differential diagnoses (spinal cord ischemia, acute cord compression, tumour, degenerative diseases of the spine, myelitis). Even with the routine sequences, the neuroradiologist should be able to detect intramedullary pathologies such as intramedullary hemorrhages, cavernomas, edema or venous congestion, extramedullary intradural alterations (such as dilated vessels or subarachnoid hemorrhages) or potential extradural manifestations of spinal cord vascular malformations (such as associated hemangiomas). When neurological symptoms and MRI suggest a vascular malformation, spinal angiography is the next diagnostic step to define the type of vascular malformation, and, thereby, to decide about the appropriate therapy. Treatment in symptomatic patients offers an improvement in the prognosis.

\section{References}

1. Thron A. Vascular anatomy of the spinal cord: neuroradiological investigations and clinical syndromes. Springer, Berlin-New York 1988, pp 124-48.

2. Lasjaunias PL, Berenstein A, terBrugge K. Surgical Neuroangiography. Vol. 1. Clinical vascular anatomy and variations. Springer, Berlin 2001, pp 240-76.

3. Grunwald I, Thron A, Reith W. Spinal angiography: vascular anatomy, technique and indications. Radiologe 2001;41:961-7.

4. Thron A, Otto J, Schroeder JM. Functional anatomy of the dural segment of spinal cord draining veins. A histological and microangiographic study. In: du Boulay G, ed. Symposium Neuroradiologicum 1990. Springer, London 1990, pp 323.

5. Rodesch G, Hurth M, Alvarez H, Tadie M, Lasjaunias PL. Classification of spinal cord arteriovenous shunts: proposal for a reappraisal - the Bicetre experience with 155 consecutive patients treated between 1981 and 1999. Neurosurgery 2002;51:374-9.

6. Krings T, Mull M, Gilsbach JM, Thron A. Spinal vascular malformations. Eur Radiol 2005;15:267-78. 
7. Thron A, Caplan LR. Vascular malformations and interventional neuroradiology of the spinal cord. In: Brandt T, Caplan LR, Dichgans J, Diener HC, Kennard C, eds. Neurological disorders. Course and treatment, 2nd ed. Academic Press, Amsterdam-Boston-London 2003, pp 517-28.

8. Thron A. Spinal dural arteriovenous fistulas. Radiologe 2001;41: 955-60.

9. Hurst RW, Kenyon LC, Lavi E, Raps EC, Marcotte P. Spinal dural arteriovenous fistula: the pathology of venous hypertensive myelopathy. Neurology 1995;45:1309-13.

10. Criscuolo GR, Oldfield EH, Doppman JL. Reversible acute and subacute myelopathy in patients with dural arteriovenous fistulas. Foix-Alajouanine syndrome reconsidered. J Neurosurg 1989;70:354-9.

11. Bradac GB, Daniele D, Riva A, Bracchi M, Stura G, Riccio A, Pagni CA. Spinal dural arteriovenous fistulas: an underestimated cause of myelopathy. Eur Neurol 1994;34:87-94.

12. Koenig E, Thron A, Schrader V, Dichgans J. Spinal arteriovenous malformations and fistulae: clinical, neuroradiological and neurophysiological findings. J Neurol 1989;236:260-6.

13. Hurst RW, Grossman RI. Peripheral spinal cord hypointensity on T2weighted MR images: a reliable imaging sign of venous hypertensive myelopathy. AJNR Am J Neuroradiol 2000;21:781-6.

14. De Marco JK, Dillon WP, Halback VV, Tsuruda JS. Dural arteriovenous fistulas: evaluation with MR imaging. Radiology 1990;175:193-9.

15. Huffmann BC, Gilsbach JM, Thron A. Spinal dural arteriovenous fistulas: a plea for neurosurgical treatment. Acta Neurochir (Wien) 1995; 135:44-51.

16. Lee TT, Gromelski EB, Bowen BC, Green BA. Diagnostic and surgical management of spinal dural arteriovenous fistulas. Neurosurgery 1998; 43:242-6; discussion 246-7.

17. Niimi Y, Berenstein A, Setton A, Neophytides A. Embolization of spinal dural arteriovenous fistulae: results and follow-up. Neurosurgery 1997; 40:675-82; discussion 682-3.

18. Rodesch G, Hurth M, Alvarez H, Tadie M, Lasjaunias PL. Spinal cord intradural arteriovenous fistulae: anatomic, clinical, and therapeutic considerations in a series of 32 consecutive patients seen between 1981 and 2000 with emphasis on endovascular therapy. Neurosurgery 2005;57:973-83.

19. Van Dijk JM, TerBrugge KG, Willinsky RA, Farb RI, Wallace MC. Multidisciplinary management of spinal dural arteriovenous fistulas: clinical presentation and long-term follow-up in 49 patients. Stroke 2002; 33:1578-83.

20. Behrens S, Thron A. Long-term follow-up and outcome in patients treated for spinal dural arteriovenous fistula. J Neurol 1999;246:181-5.

21. Rosenblum B, Oldfield EH, Doppman JL, Di Chiro G. Spinal arteriovenous malformations: a comparison of dural arteriovenous fistulas and intradural AVM's in 81 patients. J Neurosurg 1987;67:795-802.

22. Heros RC, Debrun GM, Ojemann RG, Lasjaunias PL, Naessens PJ. Direct spinal arteriovenous fistula: a new type of spinal AVM. Case report. J Neurosurg 1986;64:134-9.

23. Krings T, Ozanne A, Chng SM, Alvarez H, Rodesch G, Lasjaunias PL. Neurovascular phenotypes in hereditary haemorrhagic telangiectasia patients according to age. Review of 50 consecutive patients aged 1 day-60 years. Neuroradiology 2005;47:711-20.

24. Aminoff MJ, Logue V. Clinical features of spinal vascular malformations. Brain 1974;97:197-210.

25. Aminoff MJ, Logue V. The prognosis of patients with spinal vascular malformations. Brain 1974;97:211-8.

26. Kataoka H, Miyamoto S, Nagata I, Ueba T, Hashimoto N. Venous congestion is a major cause of neurological deterioration in spinal arteriovenous malformations. Neurosurgery 2001;48:1224-9; discussion 1229-30.
27. Gomori JM, Grossman RI, Yu-Ip C, Asakura T. NMR relaxation times of blood: dependence on field strength, oxidation state, and cell integrity. J Comput Assist Tomogr 1987;11:684-90.

28. Doppman JL, Di Chiro G, Dwyer AJ, Frank JL, Oldfield EH. Magnetic resonance imaging of spinal arteriovenous malformations. J Neurosurg 1987;66:830-4.

29. Thron A, Mull M, Reith W. Spinal arteriovenous malformations. Radiologe 2001;41:949-54.

30. Biondi A, Merland JJ, Reizine D, Aymard A, Hodes JE, Lecoz P, Rey A. Embolization with particles in thoracic intramedullary arteriovenous malformations: long-term angiographic and clinical results. Radiology 1990;177:651-8.

31. Doppman JL, Di Chiro G, Ommaya A. Obliteration of spinal-cord arteriovenous malformation by percutaneous embolisation. Lancet 1968; 1:477.

32. Djindjian R, Cophignon J, Rey A, Theron J, Merland JJ, Houdart R. Superselective arteriographic embolization by the femoral route in neuroradiology. Study of 50 cases. II. Embolization in vertebromedullary pathology. Neuroradiology 1973;6:132-42.

33. Rodesch G, Hurth M, Alvarez H, David P, Tadie M, Lasjaunias PL. Embolization of spinal cord arteriovenous shunts: morphological and clinical follow-up and results - review of 69 consecutive cases. Neurosurgery 2003;53:40-9.

34. Mourier KL, Gobin YP, George B, Lot G, Merland JJ. Intradural perimedullary arteriovenous fistulae: results of surgical and endovascular treatment in a series of 35 cases. Neurosurgery 1993;32:885-91; discussion 891.

35. Krings T, Chng SM, Ozanne A, Alvarez H, Rodesch G, Lasjaunias PL. Hereditary hemorrhagic telangiectasia in children: endovascular treatment of neurovascular malformations: results in 31 patients. Neuroradiology 2005;47:946-54.

36. Spetzger U, Gilsbach JM, Bertalanffy H. Cavernous angiomas of the spinal cord clinical presentation, surgical strategy, and postoperative results. Acta Neurochir (Wien) 1995;134:200-6.

37. Zevgaridis D, Medele RJ, Hamburger C, Steiger HJ, Reulen HJ. Cavernous haemangiomas of the spinal cord. A review of 117 cases. Acta Neurochir (Wien) 1999;141:237-45.

38. Rigamonti D, Johnson PC, Spetzler RF, Hadley MN, Drayer BP. Cavernous malformations and capillary telangiectasia: a spectrum within a single pathological entity. Neurosurgery 1991;28:60-4.

39. Russell DS, Rubinstein LJ. Pathology of tumours of the nervous system. Wiliams \& Wilkins, Baltimore 1989, pp 260-4.

40. Weinzierl MR, Krings T, Korinth MC, Reinges MH, Gilsbach JM. MRI and intraoperative findings in cavernous haemangiomas of the spinal cord. Neuroradiology 2004;46:65-71.

41. Anson JA, Spetzler RF. Surgical resection of intramedullary spinal cord cavernous malformations. J Neurosurg 1993;78:446-51.

Address for Correspondence
Timo Krings, MD
Department of Neuroradiology
University Hospital, University of Technology RWTH
Aachen
Pauwelsstraße 30
52057 Aachen
Germany
Phone (+49/241) 808-9602, Fax -2440
e-mail: tkrings@ukaachen.de

